\title{
Comparing Outcomes of Single Versus Double Venous Anastomosis in Free Flap Operation for Lower Extremity Defect Reconstruction: A Meta- Analysis
}

\author{
Suhwan Kim (1D, Kyeong-Tae Lee \\ Department of Plastic Surgery, Samsung Medical Center, Sungkyunkwan University School of Medicine, Seoul, Korea
}

\begin{abstract}
Background: Free flap operation is a common procedure for reconstructing defects of the lower extremity. However, venous congestion often results in flap failure in lower extremity reconstruction. Dual-vein anastomosis, one proposed solution to overcome this problem, has been controversial in terms of its efficacy. The objective of this study was to perform a systematic review and meta-analysis to assess the effectiveness of dual venous anastomosis on venous congestion and flap failure of the lower extremities.

Methods: PubMed/MEDLINE, Google Scholar base, and Embase were searched to identify relevant studies presenting complication rates for groups of patients who had undergone single venous or dual venous anastomosis in lower extremity reconstructions. The relative risks of the following complications between these two groups (single venous and dual venous anastomosis) were calculated: flap failure, flap necrosis, flap congestion, and take-back to operating room.

Results: A total of eight articles and 1,434 flaps were included. Double venous anastomosis was performed for 607 flaps, and single anastomosis for 827 flaps. Etiologies of defects and types of flaps were diverse. There was no significant difference in venous congestion, flap necrosis, or flap failure between the groups with one versus two vein anastomoses. However, the dual venous anastomosis group displayed a trend toward decreasing flap-related complications.

Conclusion: Although there was a trend toward decreasing flap-related complications in the double venous anastomosis group, dual venous anastomosis had no statistically significant protective effects in decreasing free flap failure in the leg.
\end{abstract}

Keywords: Free tissue flaps; Lower extremity; Anastomosis surgical

\section{Introduction}

Currently, free flap operation is one of the most popular reconstructive procedures for many types of wounds. Its success rate has risen steeply due to accumulated experience and knowledge as well as advancements in instruments. Free flap operation has been widely adopted for reconstructing lower extremity defects resulting from trauma, tumor, or infection [1]. Although recent microvascular surgical advances ensure a high rate of successful reconstruction, vascular thrombosis, particularly venous thrombosis, remains a major complication that can result in flap failure [2-6]. Especially, lower extremity microsurgery imposes relatively higher risks for these complications. The reasons are multifactorial. One suggested cause is that the lower extremity is a location that is prone to developing venous stasis [7].

Many efforts have been made to overcome the relatively high risk of venous insufficiency in lower extremity reconstruction. One method is to perform multiple vein

\section{Original Article}

Received: November 13, 2020

Revised: December 10, 2020

Accepted: December 11, 2020

\section{Corresponding author:}

Kyeong-Tae Lee, M.D.

Department of Plastic Surgery, Samsung Medical Center, Sungkyunkwan University School of Medicine, 81 Irwon-ro, Gangnam-gu, Seoul 06351, Korea

Tel: +82-2-3410-2235

Fax: +82-2-3410-0036

E-mail: skymaker26.lee@samsung.com

This is an Open Access article distributed under the terms of the Creative Commons Attribution Non-Commercial License (https://creativecommons.org/licenses/by-nc/4.0/) which permits unrestricted non-commercial use, distribution, and reproduction in any medium, provided the original work is properly cited.

(c) 2021 Korean Wound Management Society 
anastomosis. There have been many arguments regarding the potential effects of dual venous anastomosis on perfusion-related complications. According to proponents of the single vessel anastomosis, multiple anastomoses merely increase operative time and related risks of thrombosis with the growing number of anastomosis sites. They also decrease the exit velocity of each vein, making it more prone to congestion $[6,8,9]$. In contrast, those who conduct dual venous anastomosis have suggested that a multiple venous drain system can allow the veins to complement each other and reduce congestion by acting as a parallel system $[10,11]$.

Regarding the controversy surrounding double venous anastomosis in free flap operations, no solid evidence has been found as the majority of previous studies have included only small numbers of cases from single institutions. To obtain more valid conclusions, several meta-analyses have been conducted to compare outcomes between single and double venous anastomosis groups $[12,13]$. Those studies have suggested performing more than one venous anastomosis has potential benefits for reducing perfusion-related complications in free flap operation. However, the studies confined cases to head and neck reconstruction using free flaps $[14,15]$.

Thus, there have been few systematic reviews and/or metaanalysis to evaluate the potential benefits of double versus single venous anastomosis in lower extremity free flap reconstruction, when the former could have a relatively higher risk of venous thrombosis. Therefore, the objective of the present study was to perform a meta-analysis to compare outcomes of free flap operation for lower extremity reconstruction between cases with single venous drainage and those with dual venous drainage.

\section{Methods}

This meta-analysis was conducted in accordance with recommendations specified in the Cochrane Handbook for Intervention Reviews version 6.0. It is compliant with Assessing the Methodological Quality of Systematic Reviews instrument. It is also in line with the Preferred Reporting Items for Systematic Reviews and Meta-Analyses (PRISMA) statement.

\section{Search strategy}

MEDLINE, Google Scholar base, and Embase were searched for articles published from January 1, 2000 to January 1, 2020. This search was conducted using the following English language keywords combined with Boolean logical operators: "lower extremity" AND "free flap" (Title/Abstract/MeSH Terms) AND "venous anastomosis" or "double anastomosis" or "double veins" or "recipient vein" (Title/Abstract/MeSH terms). References of selected articles were also examined for more possibly relevant articles. A manual search of relevant articles and abstracts was also performed.

\section{Inclusion criteria}

The analysis included all two-arm studies comparing results of using one or more venous anastomoses in patients who underwent lower extremities reconstruction using free flaps. Randomized controlled trials, controlled clinical trials, and observational studies (retrospective and prospective) were included. Meanwhile, the following were excluded: animals, imaging, reviews or meta-analysis, case reports, and articles with overlapping study periods. Studies based on the national database were also excluded because they combined multiple institutions without being weighted.

\section{Data extraction}

Data were extracted independently by two researchers (KTL and SK). Disagreements were corrected by consensus. The data collected included: author, publication date, type of study, type and number of included flaps, etiology of defects, general characteristics of study population (age, body mass index, diabetes, smoking, other morbidities), number of venous anastomosis performed, success or failure of surgery, number of flap loss, number of venous congestion, number of re-operation, and number of overall flap-related complications.

\section{Outcomes of interest}

Primary outcomes of interest were total flap loss (flap failure), flap necrosis (total or partial), flap congestion, and the rate of take-back to operating room. These were the most significant complications related to flap operations. Total flap loss (flap failure) meant total removal of the flap without other reconstructive procedures. Flap necrosis was described as partially or totally damaged flap regardless of causes. Flap congestion referred to flaps damaged due to venous congestion caused by clots or some other reason that led to flap necrosis. Rate of take-back to operating room was the rate of re-operation due to vascular compromise.

\section{Statistical analysis}

Pooled risk for each type of perfusion-related complication was calculated and compared between cases with single ve- 
nous drainage and those with double venous drainage. Relative risks and corresponding 95\% confidence intervals (CIs) were estimated using the Mantel-Haenszel method with RevMan 5.3 software (Cochrane Collaboration, Copenhagen, Denmark). Heterogeneity for each study was assessed using Cochran $\mathrm{Q}$ statistic and $\mathrm{I}^{2}$ test. When $\mathrm{I}^{2}$ ranged from $0 \%$ to $30 \%$, the studies were regarded as homogeneous. A fixed-effects model was used to pool weighted data. Otherwise, a random-effects model was used. Publication bias was checked by funnel plots and scatter plots of intervention effects estimated from individual studies against a measure of study size. In the absence of publication bias, symmetric inverted funnelshaped plots were created. Deviation from this distribution indicated a publication bias. A P-value of less than 0.05 was considered to indicate statistical significance.

\section{Results}

The initial search identified 123 articles. According to inclusion and exclusion criteria, 113 articles were excluded after reviewing titles and abstracts. After the first exclusion, researchers reviewed full-texts for the remaining 10 studies. Finally, eight articles [16-23] with a total of 1,434 flaps were included in the systematic review (Fig. 1). All eight studies were retrospective cohort studies. Double venous anastomosis was performed for 607 flaps (42\%). Single venous anastomosis was performed for 827 flaps (58\%). Anterolateral thigh free flaps $(50 \%)$ were the most common flaps, followed by latissimus dorsi (11\%) and rectus abdominis (8\%) flaps. General characteristics of the study population are summarized in Table 1. Table 2 shows the summary of meta-analysis results. There was no statistically significant difference in the rate of flap failure, flap necrosis, or venous congestion between the two groups (single vs. dual venous anastomosis).

\section{Flap failure (total flap loss)}

Six of eight articles reported the required data (Table 3). The overall success rate was $94.1 \%$ (74 failures in 1,247 flaps). Flap failure rate was $5.1 \%$ for single venous anastomosis and $6.8 \%$ for double venous anastomosis, showing no statistically significant difference between the two (95\% CI, 0.83-2.10; $\mathrm{P}=0.23$ ) (Table 2, Fig. 2).

\section{Flap necrosis (total or partial loss)}

Seven of eight articles reported the required data for flap necrosis (Table 3). Overall flap necrosis (total or partial) ac-

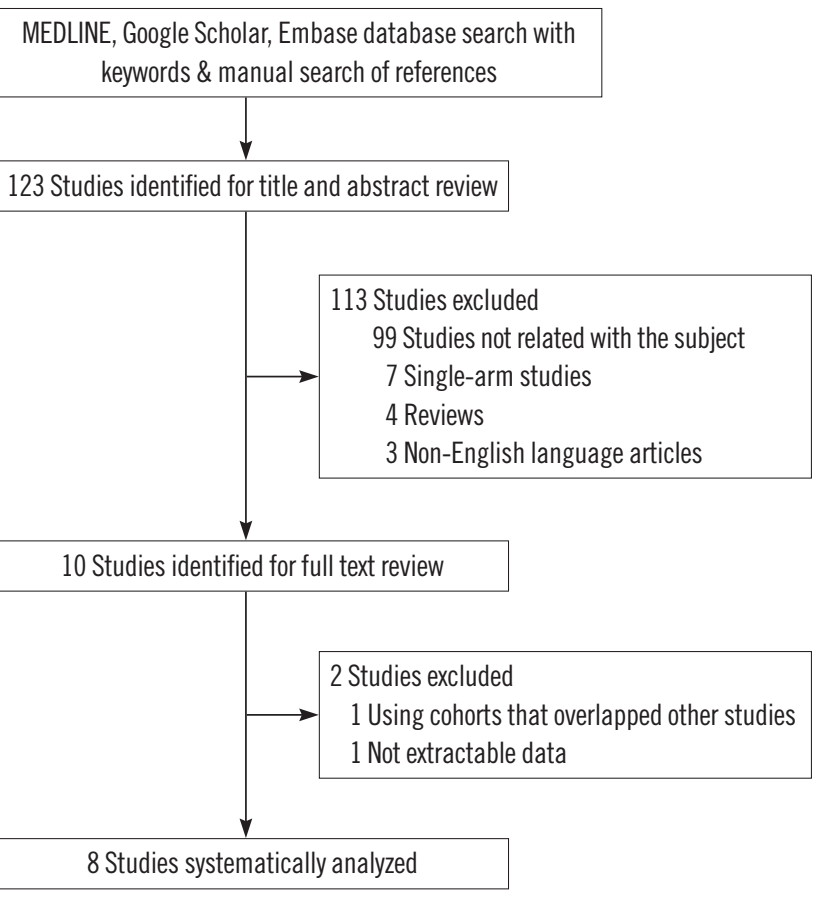

Fig. 1. PRISMA flow diagram of the study selection process. PRISMA, Preferred Reporting Items for Systematic Reviews and Meta-Analyses.

counted for $11.5 \%$ (159 cases of flap necrosis in 1,384 flaps). Flap necrosis rate was $12.7 \%$ for single venous anastomosis and $9.8 \%$ for double venous anastomosis, showing no significant difference between the two (95\% CI, 0.52-1.29; $\mathrm{P}=0.40$ ) (Table 2, Fig. 3).

\section{Flap congestion}

Six of eight articles showed the required data for flap congestion (Table 3). Total venous congestion rate was $10.0 \%$ (94 cases of congestion in 936 flaps). Venous congestion rate was $11.3 \%$ for single venous anastomosis and $8.6 \%$ for double venous anastomosis, showing no significant difference between the two (95\% CI, 0.53-1.14; $\mathrm{P}=0.20$ ) (Table 2, Fig. 4).

\section{Take-back to operating room (revision)}

Five of eight articles reported the required data for take-back to operation room (Table 3). The overall revision rate was $16.3 \%$ ( 144 cases of revision operation in 885 flaps). The revision rate was $16.9 \%$ for single venous anastomosis and $15.4 \%$ for double venous anastomosis, showing no significant difference between the two (95\% CI, 0.59-1.12; $\mathrm{P}=0.21$ ) (Table 2, Fig. 5). 
Single versus double venous anastomosis

Table 1. Characteristics of included studies

\begin{tabular}{|c|c|c|c|c|c|c|c|c|}
\hline \multirow{2}{*}{ Author (year) } & \multirow{2}{*}{ Design } & \multirow{2}{*}{ Etiology of defects } & \multirow{2}{*}{ Type of flaps used } & \multicolumn{5}{|c|}{ General characteristics of study population } \\
\hline & & & & Age $(y r)^{a)}$ & $\operatorname{BMI}\left(\mathrm{kg} / \mathrm{m}^{2}\right)^{\mathrm{a})}$ & Diabetes ${ }^{\mathrm{b})}$ & Smoking ${ }^{\text {b) }}$ & Other comorbidities \\
\hline $\begin{array}{l}\text { Abdelaal et al. } \\
\text { (2019) [16] }\end{array}$ & $\begin{array}{l}\text { Retrospective } \\
\text { study }\end{array}$ & Trauma & ALT & 23.63 & NA & NA & NA & NA \\
\hline $\begin{array}{l}\text { Bigdeli et al. } \\
\text { (2019) [17] }\end{array}$ & $\begin{array}{l}\text { Retrospective } \\
\text { study }\end{array}$ & $\begin{array}{l}\text { Trauma, } \\
\text { infection, tumor }\end{array}$ & $\begin{array}{c}\text { ALT, } \mathrm{LD}, \\
\text { parascapular, etc. }\end{array}$ & 44.0 & NA & NA & NA & NA \\
\hline $\begin{array}{l}\text { Mattos et al. } \\
\text { (2018) [18] }\end{array}$ & $\begin{array}{l}\text { Retrospective } \\
\text { study }\end{array}$ & $\begin{array}{l}\text { Traumatic, tumor, } \\
\text { infection, hardware, } \\
\text { chronic wound }\end{array}$ & ALT & 52.7 & 28.8 & 15 & 18 & NA \\
\hline $\begin{array}{l}\text { Stranix et al. } \\
\text { (2018) [19] }\end{array}$ & $\begin{array}{l}\text { Retrospective } \\
\text { study }\end{array}$ & NA & $\begin{array}{l}\mathrm{LD} \text {, rectus abdominis, } \\
\text { parascapular, ALT etc. }\end{array}$ & 37.4 & NA & NA & NA & $\begin{array}{l}\text { Malnourished, renal } \\
\text { disease, hypertension, } \\
\text { cardiovascular disease, } \\
\text { peripheral vascular } \\
\text { disease }\end{array}$ \\
\hline $\begin{array}{l}\text { Yang et al. } \\
\text { (2018) [20] }\end{array}$ & $\begin{array}{l}\text { Retrospective } \\
\text { study }\end{array}$ & $\begin{array}{l}\text { Trauma, infection, } \\
\text { chronic wound }\end{array}$ & ALT & 40.8 & NA & NA & 25 & NA \\
\hline $\begin{array}{l}\text { Heidekrueger et al. } \\
\text { (2016) [21] }\end{array}$ & $\begin{array}{l}\text { Retrospective } \\
\text { study }\end{array}$ & $\begin{array}{l}\text { Trauma, infection, } \\
\text { tumor, vascular disease }\end{array}$ & ALT & $\begin{array}{l}51.96(1 \mathrm{~V}) \\
53.39(2 \mathrm{~V})\end{array}$ & $\begin{array}{l}25.66(1 \mathrm{~V}) \\
26.25(2 \mathrm{~V})\end{array}$ & 53 & 66 & NA \\
\hline $\begin{array}{l}\text { Lorenzo et al. } \\
\text { (2011) [22] }\end{array}$ & $\begin{array}{l}\text { Retrospective } \\
\text { study }\end{array}$ & $\begin{array}{l}\text { Trauma, chronic wound, } \\
\text { infection, tumor etc. }\end{array}$ & ALT, LD & 38.6 & NA & 45 & 119 & $\begin{array}{l}\text { Hypertension, } \\
\text { cardiovascular disease }\end{array}$ \\
\hline $\begin{array}{r}\text { Spector et al. } \\
\text { (2007) [23] }\end{array}$ & $\begin{array}{l}\text { Retrospective } \\
\text { study }\end{array}$ & Trauma, infection & $\begin{array}{l}\text { Rectus abdominis, } \\
\text { LD, parascapular }\end{array}$ & 41.04 & NA & NA & NA & $\begin{array}{c}\text { Hypertension, liver } \\
\text { disease, vascular } \\
\text { disease, hyperlipidemia }\end{array}$ \\
\hline
\end{tabular}

BMI, body mass index; ALT, anterolateral thigh flap; LD, latissimus dorsi flap; 1V, 1 vein anastomosis; 2V, 2 vein anastomosis; NA, not available.

${ }^{a)}$ Mean; ${ }^{\text {bN }}$ umber.

Table 2. Pooled relative risks for complications in single or double venous anastomosis group

\begin{tabular}{|c|c|c|c|c|c|c|c|c|c|}
\hline \multirow{2}{*}{ Outcome measures } & \multirow{2}{*}{$\begin{array}{l}\text { No. of } \\
\text { studies }\end{array}$} & \multicolumn{2}{|c|}{ No. of cases } & \multicolumn{2}{|c|}{ Pooled complication rate (\%) } & \multirow{2}{*}{ RR } & \multirow{2}{*}{$95 \% \mathrm{Cl}$} & \multirow{2}{*}{ P-value } & \multirow{2}{*}{$\begin{array}{l}\text { Heterogeneity } \\
\quad\left(I^{2}, \%\right)\end{array}$} \\
\hline & & 1-Vein & 2-Vein & 1-Vein & 2-Vein & & & & \\
\hline Total flap loss & 6 & 746 & 501 & 5.1 & 6.8 & 1.32 & $0.83-2.10$ & 0.23 & 20 \\
\hline Partial flap loss & 6 & 746 & 501 & 7.1 & 3.0 & 0.75 & $0.28-1.99$ & 0.56 & 39 \\
\hline Flap necrosis (total or partial) & 7 & 758 & 590 & 13.3 & 9.8 & 0.82 & $0.52-1.29$ & 0.40 & 35 \\
\hline Flap congestion & 6 & 506 & 430 & 11.3 & 5.6 & 0.77 & $0.53-1.14$ & 0.20 & 0 \\
\hline Take-back to operation room & 5 & 521 & 364 & 16.9 & 15.4 & 0.81 & $0.59-1.12$ & 0.21 & 0 \\
\hline
\end{tabular}

$\mathrm{RR}$, relative risk; $\mathrm{Cl}$, confidence interval.

\section{Discussion}

Flap failure is one of the most devastating results for reconstructive surgeons. Though recent advances in microsurgical techniques and instruments have improved flap success rates dramatically, there always remains the risk of flap failure. Venous thrombosis is the most common reason for flap loss and the most concerning complication for microsurgeons [2-6]. To overcome this problem, double venous anastomosis has been proposed as a method to protect the flap from venous congestion that results in flap necrosis. However, there have been many debates about its effectiveness and its physiology. Opponents have argued that because of the longer operative times and increased numbers of anastomosis sites, multiple anastomoses can exhaust the surgeon and raise the risk of thrombosis. In addition, the 2 nd vein decreases the exit velocity of other veins, resulting in congestion [6,8,9]. Advocates have explained that the double venous drain system can help veins complement each other and reduce congestion by serving as a parallel system $[10,11]$. Recent meta-analysis has supported arguments for the preventive effect of double vein anastomosis against flap failure $[12,13]$. Furthermore, other 
Kim S et al.

Single versus double venous anastomosis

Table 3. Summary of outcomes of included studies

\begin{tabular}{|c|c|c|c|c|c|c|c|c|}
\hline Included studies & $\begin{array}{c}\text { No. } \\
\text { of case }\end{array}$ & $\begin{array}{c}\text { Total } \\
\text { flap loss }\end{array}$ & $\begin{array}{l}\text { Partial } \\
\text { flap loss }\end{array}$ & $\begin{array}{l}\text { Total or partial } \\
\text { flap loss }\end{array}$ & $\begin{array}{c}\text { Venous } \\
\text { congestion }\end{array}$ & $\begin{array}{c}\text { Take-back to } \\
\text { operating room }\end{array}$ & $\begin{array}{c}\text { Any } \\
\text { reoperation }\end{array}$ & $\begin{array}{l}\text { Overall flap-related } \\
\text { complications }\end{array}$ \\
\hline Abdelaal et al. (2019) [16] & 60 & & & & & & & \\
\hline 1-Vein anastomosis & 35 & 2 & 4 & 6 & 5 & 7 & NA & NA \\
\hline 2-Vein anastomosis & 25 & 2 & 3 & 5 & 4 & 5 & NA & NA \\
\hline Bigdeli et al. (2019) [17] & 50 & & & & & & & \\
\hline 1-Vein anastomosis & 33 & NA & NA & NA & 13 & 13 & NA & NA \\
\hline 2-Vein anastomosis & 17 & NA & NA & NA & 4 & 4 & NA & NA \\
\hline Mattos et al. (2018) [18] & 50 & & & & & & & \\
\hline 1-Vein anastomosis & 21 & 3 & 0 & 3 & 3 & NA & 3 & 7 \\
\hline 2-Vein anastomosis & 29 & 0 & 3 & 3 & 1 & NA & 5 & 9 \\
\hline Stranix et al. (2018) [19] & 361 & & & & & & & \\
\hline 1-Vein anastomosis & 273 & 23 & 36 & 59 & NA & 36 & NA & 71 \\
\hline 2-Vein anastomosis & 88 & 8 & 3 & 11 & NA & 9 & NA & 15 \\
\hline Yang et al. (2018) [20] & 137 & & & & & & & \\
\hline 1-Vein anastomosis & 48 & NA & NA & 10 & NA & NA & NA & NA \\
\hline 2-Vein anastomosis & 89 & NA & NA & 9 & NA & NA & NA & NA \\
\hline Heidekrueger et al. (2016) [21] & 386 & & & & & & & \\
\hline 1-Vein anastomosis & 157 & 9 & 0 & 9 & 18 & 31 & 31 & 34 \\
\hline 2-Vein anastomosis & 229 & 20 & 4 & 24 & 19 & 37 & 37 & 48 \\
\hline Lorenzo et al. (2011) [22] & 362 & & & & & & & \\
\hline 1-Vein anastomosis & 237 & 0 & 12 & 12 & 18 & NA & NA & NA \\
\hline 2-Vein anastomosis & 125 & 4 & 2 & 6 & 8 & NA & NA & NA \\
\hline Spector et al. (2007) [23] & 28 & & & & & & & \\
\hline 1-Vein anastomosis & 23 & 1 & 1 & 2 & 0 & 1 & 2 & 3 \\
\hline 2-Vein anastomosis & 5 & 0 & 0 & 0 & 1 & 1 & 1 & 1 \\
\hline
\end{tabular}

NA, not available.

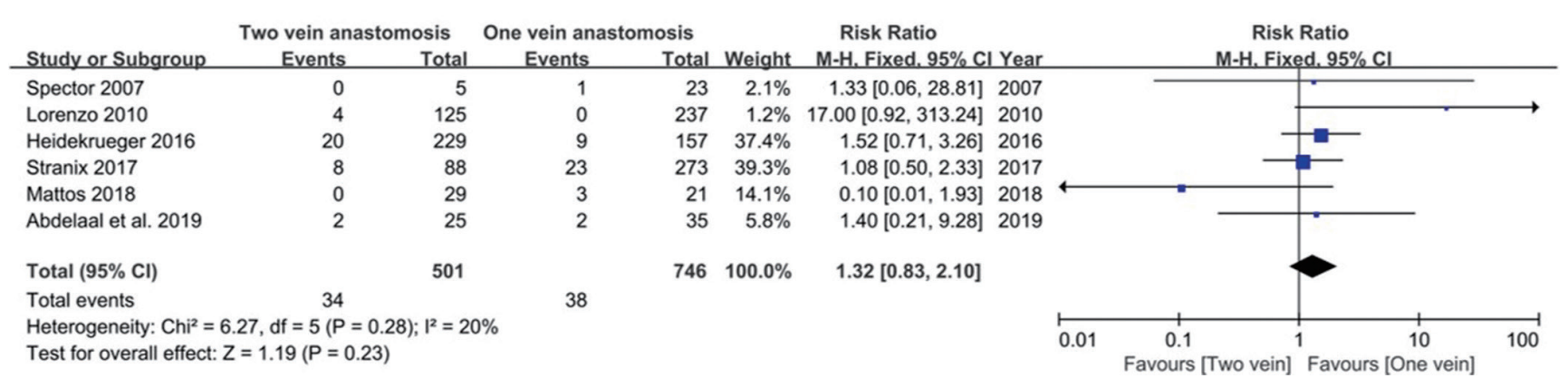

Fig. 2. Pooled relative risk of included studies concerning flap failure. $\mathrm{M}-\mathrm{H}$, Mantel-Haenszel; $\mathrm{Cl}$, confidence interval.

meta-analysis studies confined to head and neck reconstructions have also shown its protective effects [14,15].

Lower extremity reconstruction shows a higher rate of flap compromise than reconstructions in other body regions [7]. Many surgeons have adopted the double venous anastomosis technique to overcome the failure of flaps. However, the effectiveness of double anastomosis in previous literature is inconsistent for lower extremity reconstructions. Therefore, the authors pooled previous studies regarding lower extremities reconstruction comparing single vein vs. double vein anastomo- 


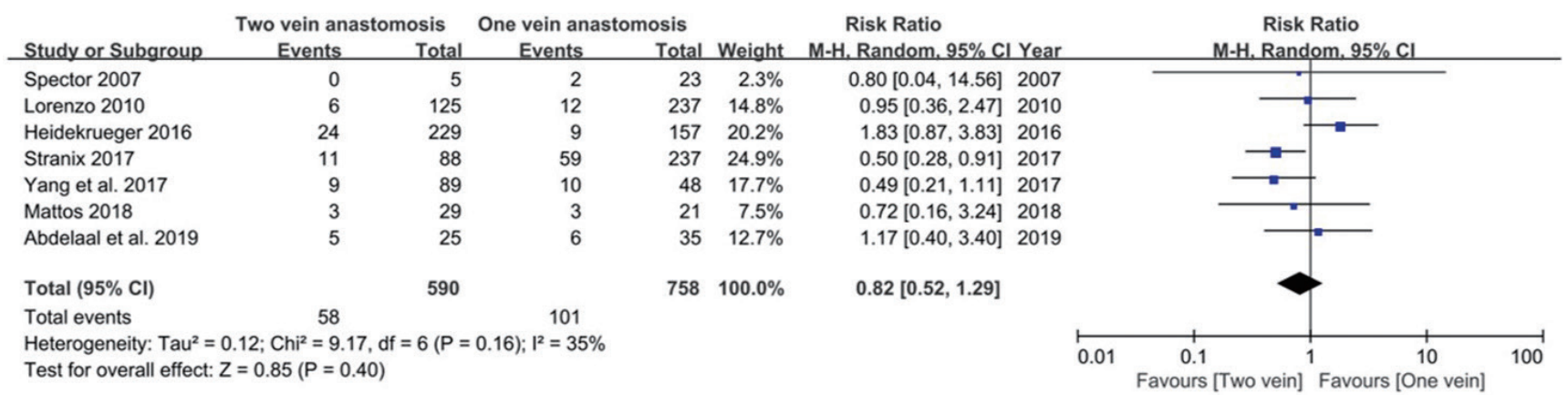

Fig. 3. Pooled relative risk of included studies concerning flap necrosis. $\mathrm{M}-\mathrm{H}$, Mantel-Haenszel; Cl, confidence interval.

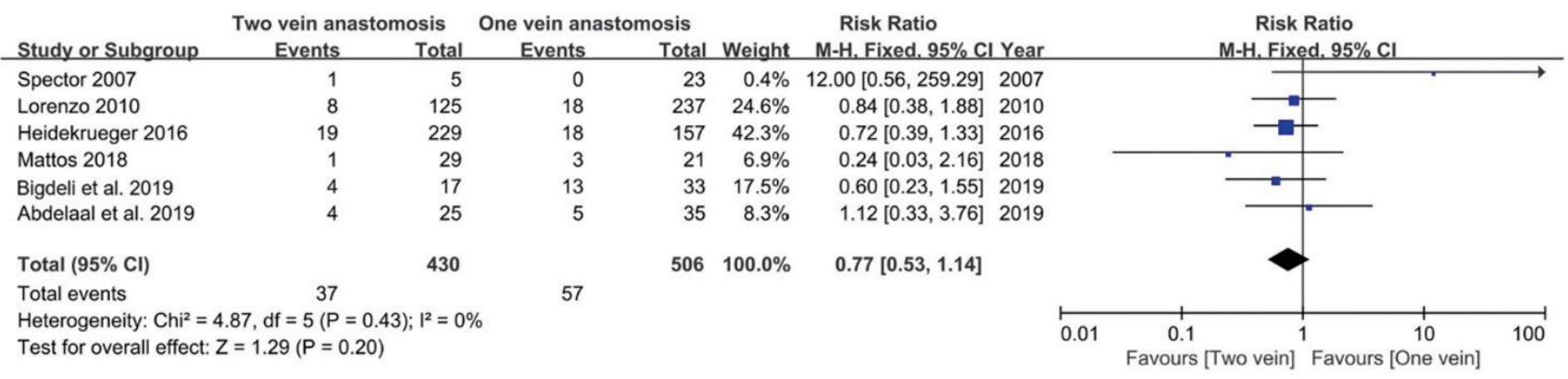

Fig. 4. Pooled relative risk of included studies concerning flap congestion. $\mathrm{M}-\mathrm{H}$, Mantel-Haenszel; Cl, confidence interval.

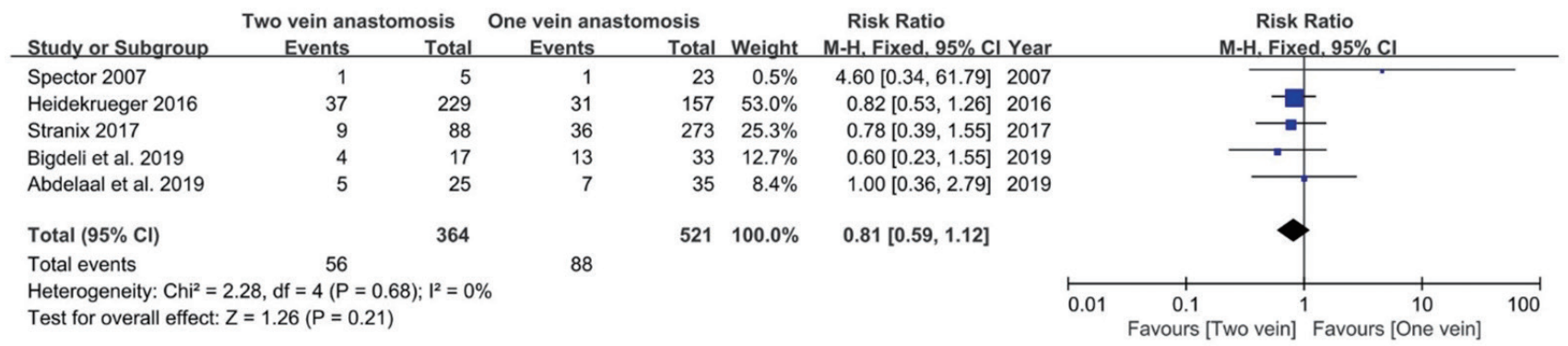

Fig. 5. Pooled relative risk of included studies concerning tack-back. $\mathrm{M}-\mathrm{H}$, Mantel-Haenszel; Cl, confidence interval.

sis. Over 1,000 free flaps were included for analysis. Results showed no statistically significant protective effect against flap failure when using double vein anastomosis. When all flap failures, partial or total flap necrosis, venous congestion, and take-back to operating room rates were compared between the two groups, there was no statistically significant difference. However, there was a trend toward decreasing flap-related complications in the group of double venous anastomosis.

With regards to flap failure and venous congestion, most of the included studies showed no differences in single versus dual venous anastomosis. Abdelaal et al. [16], Bigdeli et al. [17], Yang et al. [20], Spector et al. [23] all showed no difference between the one vein anastomosis and two vein anasto- mosis groups. Further, Lorenzo et al. [22] found that using the deep vein system is more important than using two vein anastomosis, and also reported more partial flap loss for two vein anastomosis. Mattos et al. [18] also insisted that using the deep venous system is more important than using double venous anastomosis technique. However, Stranix et al. [19] showed that dual venous anastomosis had protective effects against flap failure. They applied strict inclusion criteria to make the cohort homogenous: to demonstrate the independent effect of dual venous anastomosis, the authors enrolled patients with Gustilo III open fracture due to trauma, while the operator recorded mismatches in venous size, and also recorded whether superficial or deep venous system were used. 
In our analysis of the articles above, our results showed no significant difference between single and double venous anastomosis. This differs from the results of several recent metaanalysis studies. Such discrepancy might be related to several limitations of this study, such as the differences in etiology. Reasons for reconstructing lower extremities are very different from those for other parts of the body. In particular, lower extremities experience more trauma [24]. If patients have highenergy injuries, susceptible tissues nearby such as endothelium in vascular structures might be irreversibly damaged, increasing the possibility of thrombosis and subsequent flap failure [25]. The second suspected reason for such discrepancy was that there was no or limited demographic and comorbidity information. Patients with lower extremity defects who smoked, had diabetes or vascular disease are known to be challenging subjects for microsurgical procedures. Therefore, these comorbidities need to be analyzed to reduce potential confounding effects. Unfortunately, we could only find limited data on comorbidities for the study population.

Another limitation of this study is there were few studies and flap cases included. Even though we included all lower extremity reconstructions to compare one-vein versus two-vein anastomosis, only a few articles were ultimately included, and compared several parts of the lower extremities. Also, as the articles included in the final analysis were heterogenous with different or insufficiently reported adjusted confounders, these factors were not considered in our analysis, further limiting the meta-analysis. Therefore, further meta-analysis with a larger number of well-designed studies would be required to obtain more solid conclusions.

The authors compared one vein versus double vein anastomosis for reconstructing lower extremity defects. There was no statistically significant difference in the rate of total/partial flap loss or venous congestion. However, there was a trend toward decreasing flap-related complications in the group of double venous anastomosis.

\section{Conflict of interest}

No potential conflict of interest relevant to this article was reported.

\section{ORCID iDs}

Suhwan Kim

Kyeong-Tae Lee https://orcid.org/0000-0002-3177-6878

https://orcid.org/0000-0002-9070-9296

\section{References}

1. Swanson E, Boyd JB, Manktelow RT. The radial forearm flap: reconstructive applications and donor-site defects in 35 consecutive patients. Plast Reconstr Surg 1990;85:258-66.

2. Sigurdsson GH. Perioperative fluid management in microvascular surgery. J Reconstr Microsurg 1995;11:57-65.

3. Hirigoyen MB, Zhang WX, Weinberg $\mathrm{H}$, et al. Periadventitial delivery of heparin in the prevention of microvenous thrombosis. J Oral Maxillofac Surg 1996;54:1097-102.

4. Francel TJ, Vander Kolk CA, Yaremchuk MJ. Locally applied hypothermia and microvascular muscle flap transfers. Ann Plast Surg 1992;28:246-51.

5. Tran NV, Buchel EW, Convery PA. Microvascular complications of DIEP flaps. Plast Reconstr Surg 2007;119:1397405 .

6. Futran ND, Stack BC Jr. Single versus dual venous drainage of the radial forearm free flap. Am J Otolaryngol 1996;17:112-7.

7. Harashina T. Analysis of 200 free flaps. Br J Plast Surg 1988; 41:33-6.

8. Hanasono MM, Kocak E, Ogunleye O, et al. One versus two venous anastomoses in microvascular free flap surgery. Plast Reconstr Surg 2010;126:1548-57.

9. Fernandez EJ, Nadal RD, Gonzalez SM, et al. The effect of stasis on a microvascular anastomosis. Microsurgery 1983;4: 176-7.

10. Ichinose A, Terashi H, Nakahara M, et al. Do multiple venous anastomoses reduce risk of thrombosis in free-flap transfer? Efficacy of dual anastomoses of separate venous systems. Ann Plast Surg 2004;52:61-3.

11. Ross GL, Ang ES, Lannon D, et al. Ten-year experience of free flaps in head and neck surgery: how necessary is a second venous anastomosis? Head Neck 2008;30:1086-9.

12. Riot S, Herlin C, Mojallal A, et al. A systematic review and meta-analysis of double venous anastomosis in free flaps. Plast Reconstr Surg 2015;136:1299-311.

13. Ahmadi I, Herle P, Rozen WM, et al. One versus two venous anastomoses in microsurgical free flaps: a meta-analysis. J Reconstr Microsurg 2014;30:413-8.

14. Chaput B, Vergez S, Somda S, et al. Comparison of single and double venous anastomoses in head and neck oncologic reconstruction using free flaps: a meta-analysis. Plast Reconstr Surg 2016;137:1583-94.

15. Christianto S, Lau A, Li KY, et al. One versus two venous anastomoses in microsurgical head and neck reconstruction: a cumulative meta-analysis. Int J Oral Maxillofac Surg 
2018;47:585-94.

16. Abdelaal M, Gaber A. Safety of single vein anastomosis versus double venous anastomosis in ALT perforator flap in foot and leg reconstruction. Mod Plast Surg 2019;9:65-73.

17. Bigdeli AK, Gazyakan E, Schmidt VJ, et al. Long-term outcome after successful lower extremity free flap salvage. J Reconstr Microsurg 2019;35:263-9.

18. Mattos D, Diamond S, Chattha AS, et al. Venous anastomoses in anterolateral thigh flaps for the lower extremity: vessel selection in lieu of obligatory number. Ann Plast Surg 2018 May 14 [Epub]. https://doi.org/10.1097/SAP.000000000000 1431.

19. Stranix JT, Lee ZH, Anzai L, et al. Optimizing venous outflow in reconstruction of Gustilo IIIB lower extremity traumas with soft tissue free flap coverage: are two veins better than one? Microsurgery 2018;38:745-51.

20. Yang X, Yan H, Fan Y, et al. Risk factors of free anterolateral thigh flap failure for reconstruction of lower-limb defects: a 10-year experience. Int J Clin Exp Med 2018;11:11028-37.
21. Heidekrueger PI, Ehrl D, Heine-Geldern A, et al. One versus two venous anastomoses in microvascular lower extremity reconstruction using gracilis muscle or anterolateral thigh flaps. Injury 2016;47:2828-32.

22. Lorenzo AR, Lin CH, Lin CH, et al. Selection of the recipient vein in microvascular flap reconstruction of the lower extremity: analysis of 362 free-tissue transfers. J Plast Reconstr Aesthet Surg 2011;64:649-55.

23. Spector JA, Levine S, Levine JP. Free tissue transfer to the lower extremity distal to the zone of injury: indications and outcomes over a 25-year experience. Plast Reconstr Surg 2007; 120:952-9.

24. Gorman PW, Barnes CL, Fischer TJ, et al. Soft-tissue reconstruction in severe lower extremity trauma: a review. Clin Orthop Relat Res 1989;(243):57-64.

25. Grotting JC. Prevention of complications and correction of postoperative problems in microsurgery of the lower extremity. Clin Plast Surg 1991;18:485-9. 